\title{
Needle in a haystack: migration of ventriculoperitoneal shunt into scrotum of infant
}

\author{
Harsh Deora', Anil Sharma ${ }^{1,2}$, K. V. L. N. Rao ${ }^{1 *}$, Sampath Somanna ${ }^{1}$ and Vikas V ${ }^{1}$
}

\begin{abstract}
Background: Ventriculoperitoneal shunt malpositions are known complications which tend to increase the morbidity and recovery time of an elegant procedure. Distal malpositions into subcutaneous space due to improper closure or positioning can lead to shunt failure. Migration to the scrotum due to a patent processus vaginalis is, however, reported only in a handful of cases and, thus, needs to be highlighted and reported.

Results: We report a case of congenital hydrocephalus that underwent shunting at the age of 3 months and reported to be 9 months later with the shunt tube being felt in the scrotum. Repositioning along with herniotomy was performed.
\end{abstract}

Conclusions: A rare occurrence, scrotal migration, needs to recognized and reported. Potential preventive measures include truncation stiches and laproscopic assisted insertion.

Keywords: Ventriculoperitoneal shunts, Shunts, Distal migration, Scrotal migration

\section{Background}

Ventriculoperitoneal shunts (VPS) are the most commonly performed operative procedures to treat hydrocephalus in children. Catheters are placed such that they allow drainage of CSF from the ventricle to the peritoneal cavity. Abdominal catheter placement can be done using open technique or laproscopic assistance. Although, laparoscopic assistance has been shown to reduce malposition rates and distal shunt failure, many centers still employ an open technique for inserting the abdominal end intraperitoneally [1]. After placement, however, complications are frequent, especially in children. Shunt migration through a patent processus vaginalis within the scrotal sac is a rare event, with only a few cases reported till date [2-15]. We report a case of scrotal migration of VP shunt in a 1-year-old boy, through patent processus vaginalis, who had a background history of congenital hydrocephalus.

\footnotetext{
* Correspondence: neuronarsi@gmail.com

${ }^{1}$ Department of Neurosurgery, National Institute of Mental Health and

Neurosciences (NIMHANS), Bangalore 560029, India

Full list of author information is available at the end of the article
}

\section{Case presentation}

A 1-year-old male child with congenital hydrocephalus underwent ventriculoperitoneal (VP) shunt, using medium pressure Chhabra's ventriculoperitoneal shunt, 9 months ago. The patient presented to us with a tube-like structure palpable within the scrotum, felt by the mother while bathing him. There were no clinical signs of shunt malfunction. On physical examination involving affected side of inguinal scrotal region, a tube-like structure was palpable going from the abdomen to the scrotum confirming the herniation for the shunt through the processus vaginalis. On the opposite side, however, there was no hernia felt via crying reflex or finger invagination. Plain radiograph of the chest and abdomen (Fig. 1) showed the long peritoneal catheter shunt tube in the abdomen which was twisted and kinked in its mid portion and its distal end in the right scrotum. Plain computed tomography (CT) scan of head showed decompressed ventricular system, with ventricular shunt catheter in situ (Fig. 2).

The patient underwent repositioning of the distal shunt catheter along with obliteration of the patent processus vaginalis via a separate inguinal incision with the assistance of a pediatric surgeon. On retrospectively analyzing the case via file history and examination records, 


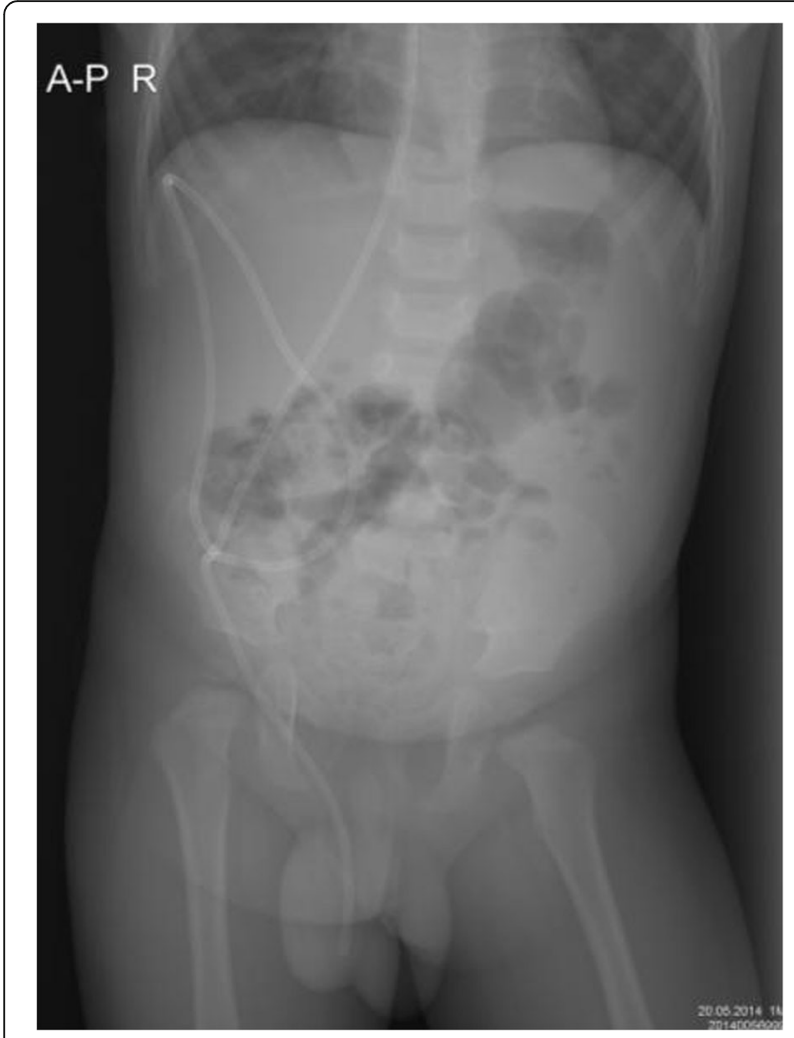

Fig. 1 AP radiograph of the chest and abdomen showed shunt tube in the abdomen which was twisted and kinked in its mid portion and its distal end in the right scrotum

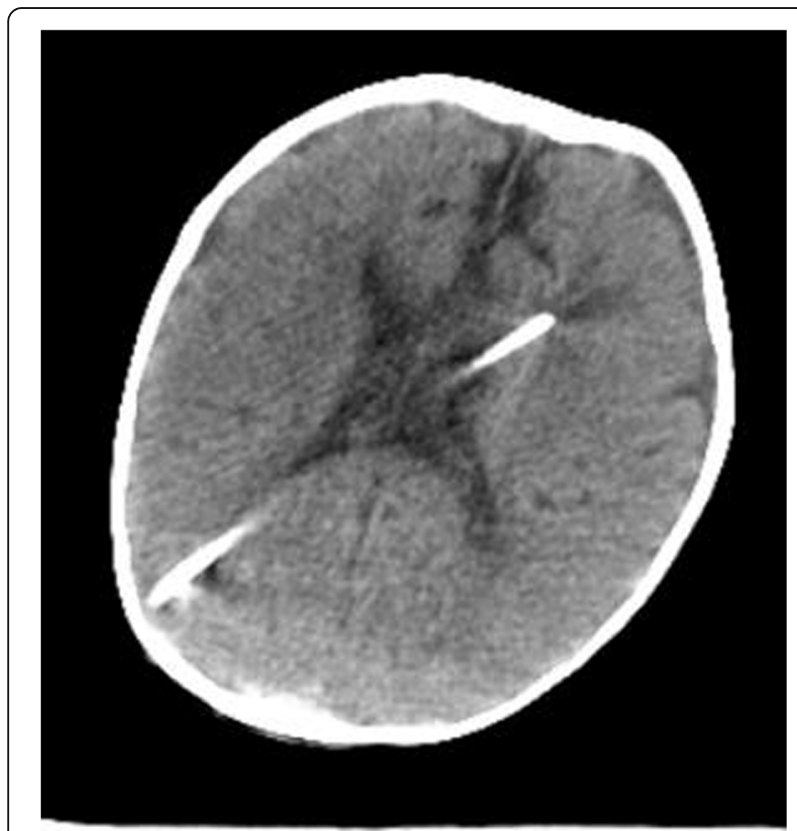

Fig. 2 CT scan of head showing decompressed ventricular system, with ventricular shunt catheter in situ it was noticed that a primary hernia or hydrocele had been excluded by clinical examination prior to shunt at the age of 3 months. He was kept for observation postoperatively for a few days and discharged after confirming patency of shunt with the help of a shunt tap and reduced ventricle size on repeat $\mathrm{CT}$.

\section{Discussion}

The distal catheter of VPS can migrate into various body parts including abdominal wall, hollow viscous, vagina, mediastinum, bladder, scalp/sub-galeal space, neck, mouth, breast, thoracic cavity, pulmonary artery, intracardiac, and umbilicus [15]. The reported incidence of distal migration of VP shunt is $10 \%$. Migration into the scrotum is a very rare phenomenon that has been reported in nearly 30 case reports in the literature. Patent processus vaginalis can be present up to $30 \%$ of infant, and increasing abdominal pressure following shunt insertion contributes to the mechanism of shunt migration [15]. Most of these problems are due to free position of the lower end in the general peritoneal cavity and thus are able to migrate to any site. Many possible mechanisms have been suggested to explain these observations, yet they remain speculative in nature. It could be due to different causes; mechanical factors such as diaphragmatic movement, peritoneal attachments, intestinal peristalsis, and repeated traction of the peritoneal catheter could be attributed for migration or as Rowe et al. pointed out the patent processus vaginalis [16]. The distal catheter enters the scrotum from the patent processus vaginalis which is patent in $30 \%$ of children under 1 year of age. Increased abdominal pressure due to cerebrospinal fluid infusion in the smaller peritoneal cavity in pediatric patients through the shunt system may prevent obliteration of the processus vaginalis and facilitates migration of the VP shunt into the scrotum. The involvement of the right-sided scrotum was prevailing, and this can be due to the fact that the right testicle descends later than the left testicle. Primary prevention can be done by searching for a patent processus vaginalis (PPV) at the time of the first VP shunt placement. Laparoscopy can be used to visualize an appropriate window for the VP shunt insertion and to search for a PPV. If a PPV or an occult hernia is found, then hernia repair should be performed primarily in the same sitting.

Most of the VP shunt migration occurs during infancy and within 6 months of implantation, though in our case, it was after 9 months. The average interval from placement of a ventriculoperitoneal shunt to development of clinically evident hernia or hydrocele was $24 \mathrm{~h}$ to 6 months as found by Oktem et al. [17]. Only two cases of distal catheter migration into scrotum occurred in adolescent patients as well as two other cases occurred in an adult males. The residual peritoneal cavity volume is linearly correlated with the body surface area $\left(80 \mathrm{ml} / \mathrm{m}^{2}\right)$; pediatric patients have a higher 
tendency to have VPS distal catheter migrate into the scrotum due to patent processus vaginalis and smaller peritoneal cavity [6].

Pandey et al. compared the outcome following placement of a VP shunt in the general peritoneal cavity with that in the right suprahepatic space and found that the complication rate with peritoneal placement was $31.43 \%$ while with suprahepatic placement it was only $3 \%$. There was no incidence of inguinoscrotal migration of the shunt if its distal end is placed in a right suprahepatic space and suggested an alternative site of peritoneal end placement in the suprahepatic space to reduce abdominal complications with good results [18].

The issue of the length of peritoneal catheter and complications related to it has been discussed in the literature and suggests that use of full-length peritoneal shunt catheter is not associated with an increase in complications and eliminates the need to lengthen the peritoneal catheter for growth of the child $[10,11]$.

Scrotal migration of the distal VP shunt can lead to secondary hydrocoele, incarceration of catheter, and shunt malfunction which in turn can cause worsening of the hydrocephalus. A plain radiographic shunt series should be performed to assess integrity of VP shunt. Herniotomy with repositioning of the shunt tube is the treatment of choice [15].

While our case may not be unique, it highlights the need for reporting of such cases. Despite it being a known complication, primary prevention by primary repair of hernia using laparoscopy for distal end insertion is not being practiced as standard of care especially in pediatric shunts. We hope, by reporting this case, that issues of length of catheter inserted, need for examination of hernia/hydrocele, distal end placement, early recognition of migration, and prompt repair are addressed.

\section{Conclusions}

Migration of distal ends of VPS is a reality, especially in infants with a patent processus vaginalis. Suprahepatic placement of the shunt could be a better choice for these cases. A truncation stich at the site of abdominal opening to anchor the distal tube is also a viable option. However, at presentation, repositioning and prompt herniotomy is the call of the hour.

\section{Abbreviations}

VP: Ventriculo-peritoneal; VPS: Ventriculo-peritoneal shunt

\section{Funding}

There is no external funding for publication of this article.

\section{Availability of data and materials}

All datasets on which the conclusions of the manuscript are based are either deposited in publicly available repositories or presented in the main paper.
Authors' contributions

Dr. HD and Dr. AS contributed to the data collection and writing of the manuscript. Dr. KVLNR, Dr. SS, and Dr. W contributed to the cross-checking and editing of the manuscript. All authors read and approved the final manuscript.

\section{Authors' information}

$\mathrm{HD}$ and $\mathrm{AS}$ are senior residents involved in the management/surgery of the case.

KVLNR, SS, and W are consultants involved in the decision-making in the case.

\section{Ethics approval and consent to participate}

Ethics approval was taken from the Institute Ethical committee (NIMHANS Ethical Committee) prior to reporting of case. Consent to participate was taken from parents of the infant prior to reporting of case.

\section{Consent for publication}

Consent for publication was taken from parents of the infant prior to reporting of case.

\section{Competing interests}

The authors declare that they have no competing interests.

\section{Publisher's Note}

Springer Nature remains neutral with regard to jurisdictional claims in published maps and institutional affiliations.

\section{Author details}

'Department of Neurosurgery, National Institute of Mental Health and Neurosciences (NIMHANS), Bangalore 560029, India. ${ }^{2}$ All India Institute of Medical Sciences, Raipur, India.

Received: 5 November 2017 Accepted: 28 November 2017

Published online: 02 May 2018

\section{References}

1. Couldwell WT, LeMay DR, McComb JG. Experience with use of extended length peritoneal shunt catheters. J Neurosurg. 1996;85:425-7.

2. Agarwal T, et al. Unusual complication of ventriculoperitoneal shunt surgery. J Pediatr Neurosci. 2009;4:122-3. https://doi.org/10.4103/1817-1745.57340.

3. Bristow DL, Buntain WL, James HL. Ventriculoperitoneal (VP) shunt migration causing an acute scrotum: a case report of Doppler evaluation. J Pediatr Surg. 1978;13:538-9

4. Kita D, Hayashi Y, Kinoshita M, Ohama K, Hamada J. Scrotal migration of the peritoneal catheter of a ventriculoperitoneal shunt in a 5-year-old male: case report. Neurol Med Chir (Tokyo). 2010:50:112-1125.

5. Korfias S, Alexiou GA, Vlachakis E, Sakas DE. Scrotal swelling due to migration of the abdominal catheter of a cyst-peritoneal shunt. Clin Neurol Neurosurg. 2013;115:1918-9. https://doi.org/10.1016/j.clineuro.2013.03.012.

6. Lee BS, Vadera S, Gonzalez-Martinez JA. Rare complication of ventriculoperitoneal shunt. Early onset of distal catheter migration into scrotum in an adult male: case report and literature review. Int J Surg Case Rep. 2015:6c:198-202. https://doi.org/10.1016/j.ijscr.2014.09.032.

7. Mohammadi A, Hedayatiasl A, Ghasemi-Rad M. Scrotal migration of a ventriculoperitoneal shunt: a case report and review of literature. Med Ultrason. 2012;14:158-60.

8. Panda SS, Singh A, Bajpai M, Sharma N. Shunt in scrotum: unusual complication in operated cases of hydrocephalus. BMJ Case Rep. 2013;2013 https://doi.org/10.1136/bcr-2013-201854.

9. Rehm A, Bannister CM, Victoratos G. Scrotal perforation by a ventriculoperitoneal shunt. Br J Neurosurg. 1997:11:443-4.

10. Shahizon AM, Hanafiah M, Hing EY, Julian MR. Migration of a fractured ventriculoperitoneal shunt into the scrotum: a rare complication. BMJ Case Rep. 2013;2013 https://doi.org/10.1136/bcr-2013-200609.

11. Shankar B, Narayanan R, Paruthikunnan SM, Kulkarni CD. Scrotal migration of ventriculoperitoneal shunt. BMJ Case Rep. 2014;2014 https://doi.org/10.1136/bcr-2014-204404.

12. Silver RI, Docimo SG. A ventriculoperitoneal shunt masquerading as a paratesticular tumor. J Pediatr Surg. 2000;35:1407-8. 
13. Walsh AR, Kombogiorgas D. Coiled ventricular-peritoneal shunt within the scrotum. Pediatr Neurosurg. 2004;40:257-8. https://doi.org/10.1159/000082304.

14. Ward JF, Moquin RR, Maurer ST. Expanding the differential diagnosis of the acute scrotum: ventriculoperitoneal shunt herniation. Urology. 2001;58:281.

15. Ricci C, Velimirovic BM, Fitzgerald TN. Case report of migration of 2 ventriculoperitoneal shunt catheters to the scrotum: use of an inguinal incision for retrieval, diagnostic laparoscopy and hernia repair. Int I Surg Case Rep. 2016;29:219-22.

16. Rowe Ml, Copelson LW, Clatworthy HW. The patent processus vaginalis and the inguinal hernia. J Pediatr Surg. 1969;4:102-7.

17. Oktem IS, Akdemir H, Koc K, Menku A, Tucer B, Selcuklu A, et al. Migration of abdominal catheter of ventriculoperitoneal shunt into the scrotum. Acta Neurochir. 1998;140:167-70.

18. Pandey A, Gangopadhyay AN, Sharma SP, Upadhyaya VD, Kumar V, Gopal SC, et al. Placement of the peritoneal end of a ventriculoperitoneal shunt in the suprahepatic space: does it improve prognosis? Pediatr Neurosurg. 2009:45:6-10.

\section{Submit your manuscript to a SpringerOpen ${ }^{\circ}$ journal and benefit from:}

- Convenient online submission

- Rigorous peer review

- Open access: articles freely available online

- High visibility within the field

- Retaining the copyright to your article

Submit your next manuscript at $\boldsymbol{s p r i n g e r o p e n . c o m ~}$ 